TAPROBANICA, ISSN 1800-427X. January, 2015. Vol. 07, No. 01: pp. 1-7, pls. 1-3.

(C) Research Center for Climate Change, University of Indonesia, Depok, Indonesia

\& Taprobanica Private Limited, Homagama, Sri Lanka

www.taprobanica.org

\title{
A NEW MONTANE SPECIES OF THE GENUS Pareas WAGLER, 1830 (SQUAMATA: PAREATIDAE) FROM NORTHERN MYANMAR
}

\author{
Gernot Vogel*
}

* Society for Southeast Asian Herpetology, Im Sand 3, D-69115 Heidelberg, Germany

E-mail: gernot.vogel@t-online.de

\begin{abstract}
A new species of the genus Pareas is described from northern Myanmar. It differs from all other known species of the genus by coloration, which is mainly uniform, and its size (one of the largest species in the genus). Furthermore it is characterized by a low number of supralabials (six), a loreal that touches the orbit, presence of a presubocular and absence of a preocular. The new species was found at an elevation of $1890 \mathrm{~m}$ a.s.l. and is regarded as an inhabitant of high elevation mountainous areas.
\end{abstract}

Keywords: Asia, Colubroidea, Oriental region, Pareas vindumi sp. nov., taxonomy

\section{Introduction}

The genus Pareas Wagler, 1830 is widely distributed in the Oriental region. Since the description of Pareas nigriceps Guo \& Deng, 2009 and the revalidation of Pareas chinensis (Barbour, 1912) by Guo et al. (2011) the genus currently comprised 11 species. Although there have been several revisions (Rao \& Yang 1992, Ota et al. 1997, Guo \& Deng 2009, Guo et al. 2011), its phylogeny is only partially known (Guo et al. 2011). Several species groups of the genus await clarification of their systematics and an increase in the species number can be expected. Astonishingly, little is known about the natural history of the members of this genus, despite the fact that in some areas, species of this genus are quite common. Together with the monotypic genus Aplopeltura A. Duméril, 1853, and Asthenodipsas Boie, 1827, with five species (Loredo et al. 2013), Pareas is included in the family Pareatidae (Pyron et al. 2011). Snakes of the genus Pareas are mainly arboreal, nocturnal, and feed generally on slugs and snails (Götz, 2002).

In 1999, the National Science Foundation funded a joint three-year collaboration between the Nature and Wildlife Conservation Division, Forestry Department of Myanmar, the California Academy of Sciences, and the Smithsonian Institution, to catalogue the amphibian and 
reptile species of Myanmar. The core of the project was specimen-based surveys conducted primarily by a trained field team chosen from employees of the Nature and Wildlife Conservation Division, Forestry Department. In the course of this project, a large unusual specimen of the genus Pareas was collected and deposited in the collection of the CAS, which subsequently herein is described as a new species.

\section{Materials and Methods}

The specimen of the undescribed species was compared with a total of 128 preserved specimens of all known species of the genera Pareas, Asthenodipsas and Aplopeltura with the exception of Pareas iwasakii from Japan. The external morphological characters and coloration of all the specimens were examined in detail, and the examined materials are listed in Appendix 1.

A total of 40 morphological characters were recorded for each specimen (see Appendix 2). Not all of these characters were useful to distinguish between species in this study, but all of them were compared because they may be of use for further taxonomic studies.

Measurements were taken with a slide-caliper to the nearest $0.1 \mathrm{~mm}$, except body and tail lengths, which were measured to the nearest of one millimeter with a measuring tape. The number of ventral scales was counted according to Dowling (1951). Half ventrals were counted as one. The first enlarged shield anterior to the ventrals was regarded as a preventral and was present in all examined specimens. The first scale under the tail meeting its opposite was regarded as the first subcaudal, and the terminal scute was not included in the number of subcaudals. The dorsal scale rows were counted at one head length behind head, at mid-body, and at one head length before vent. In the number of supralabials touching the subocular, those only touching the presubocular were not included. Infralabials were considered being those shields that were completely below a supralabial and bordering the mouth gap. Usually the last supralabial shield was a very large shield, much larger than other supralabials. Smaller shields behind this enlarged shield do not border the mouth gap (only the connecting muscle) and were excluded in the sublabial scales count, despite the fact that they were covered by the supralabials. The first sublabial was defined as the scale that starts between the posterior chin shield and the infralabials and that borders the infralabials. Values for paired head characters were recorded on both sides of the head, and were reported in a left / right order. The sex was determined by dissection of the ventral tail base.

Museum abbreviations: BMNH: The Natural History Museum, London, UK; CAS: California Academy of Sciences, San Francisco, USA; CIB: Chengdu Institute of Biology, Chengdu, People's Republic of China; DL: Ding Lee's private collection, Chengdu, People's Republic of China; FMNH: Field Museum of Natural History, Chicago, USA; MNHN: Muséum national d'Histoire naturelle, Paris, France; MZB: Museum Zoologicum Bogoriense, Bogor, Java, Indonesia; NMW: Naturhistorisches Museum Wien, Vienna, Austria; PSGV: Gernot Vogel's private collection, Heidelberg, Germany; RMNH: Nationaal Natuurhistorisch Museum (Naturalis), Leyden, The Netherlands; SMF: Natur-Museum und Forschungs-Institut Senckenberg, Frankfurt-am-Main, Germany; ZFMK: Zoologisches Forschungsmuseum Alexander Koenig, Bonn, Germany; ZMA: Zoölogisch Museum Amsterdam, Amsterdam, The Netherlands; ZMB: Zoologisches Museum für Naturkunde der Humboldt-Universität zu Berlin, Berlin, Germany; ZSM: Zoologische Staatssammlung, München, Germany.

Other abbreviations: SVL: Snout-vent length; TaL: Tail length; TL: Total length; Rel TL: Relative tail length TaL/TL, Ve: ventral scales; Sc: subcaudal scales; Lo: loreal scale.

\section{Results}

\section{Pareas vindumi sp. nov.} (Figs. 1-3)

Holotype: adult female (527 mm SVL), CAS 248147 (field number CAS-MHS-28983); Chipwi Township, Lukpwi village (254'ㄴ⒈7996"N, 98¹9' 22.7994"E, 1890 m asl), Kachin State, Myanmar, coll. M. Hlaing, S. L. Oo, Z. H. Aung, K. S. Lwin, and Y. M. Win, 28 July 2009.

Diagnosis: A species of the genus Pareas characterized by a large size (in the single known specimen $657 \mathrm{~mm}$ ); loreal widely touching orbit; vertebral scales smooth and not 
enlarged; dorsal scales smooth; 178 ventrals in the single known female, males unknown; 61 subcaudals in the single known female; relative TL 0.198 in the single known female; 6 supralabials with SL 3-4 touching the subocular; 6 infralabials, first ones touching behind the mental shield; no pre- or postocular, one presubocular; 2 anterior temporals; body pattern uniform and no markings on the head, no collar. The new species can be diagnosed by its large size, low number of supralabials and infralabials, and unusual uniform pattern for this genus.

Description of the holotype: Female, SVL 527 mm; TaL 130 mm; TL 657 mm; Rel TL: 0.198. Body elongate, laterally compressed; head distinct from the neck, snout blunt; eye moderate, dark. Rostral slightly visible from above; a single nasal; two internasals, widely in contact with each other with a diagonal suture; two large irregular pentagonal prefrontals, much larger than internasals and with a slightly diagonal suture between; one pentagonal-shaped frontal, longer than wide, smaller than parietals; no preocular; no postoculars; one triangular presubocular, touching second and third supralabials, loreal and orbit; one subocular, surrounding about one third of the eye, touching the supraocular; 1/1 loreal, broadly touching eye, longer than wide, elongated, in contact with second supralabial, presubocular, prefrontal, internasal and nasal; $6 / 6$ supralabials, $3^{\text {rd }}$ and $4^{\text {th }}$ SL touching the subocular, none reaching the eye, $6^{\text {th }}$ by far the largest, elongate; $1 / 1$ supraocular; $2 / 2$ anterior temporals and $3 / 3$ posterior temporals; $6 / 6$ infralabials, $1^{\text {st }}$ pair in contact with each other. Dorsal scales in 15-1515 rows, smooth. Vertebral row not enlarged. No apical pits. $178 \mathrm{Ve}$ (+ one preventral); $61 \mathrm{Sc}$; cloacal plate single.

Etymology: This species is named in honour of Jens Vindum (CAS, San Francisco, USA), for his enormous contributions to the CAS expeditions to Myanmar. I suggest the following common names: Vindum's Slug Eater (English), Vindums Schneckenfresser (German).

Colour in preservative: Head and body chocolate-brown with very fine dark and pale specklings, only visible in close-up view; no markings or bands on the body and head; head the same colour as body, paler in the temporal region, whitish-cream on upper and lower labials, head sides with fine speckles, more intense on the sutures of the upper labials and in the temporal region; lower labials also speckled but less intensively than supralabials; eye black; underside of head coloured like ventral side of the body, also with fine speckles. Venter whitish-cream with fine specklings, more concentrated to the base of the ventrals. Tail coloured like body, ventrally heavily speckled.

Distribution and natural history: Pareas vindumi sp. nov. is currently only known by an unique specimen from the Chipwi Township region of Kachin State, Myanmar. It should be expected in the surrounding mountainous areas and in neighboring Republic of China. The holotype was found at an elevation of $1,890 \mathrm{~m}$ a.s.l., at about 9.00 PM. Nothing else was recorded, but obviously this is a species living at high elevations. No further information is known on the biology of this species.

\section{Discussion}

In Guo \& Deng (2009), the new species keys out as P. monticola (Cantor, 1839). The pholidosis is most similar to P. boulengeri (Angel, 1920). However both species have a banded pattern and distinct neck- and head markings as well as more supralabials and more infralabials (Figs. 4 $\& 5)$. I refrain from providing a new key, due to the fact that several publications on this genus are about to be published and the key would be outdated shortly after it is printed.

Pareas vindumi sp. nov. can be distinguished from the other members of the genus Pareas as follows (values of $P$. vindumi sp. nov. vs. the compared species in brackets). Only the most diagnostic differences are listed. The data of the compared species were taken from specimens listed in Appendix 1 and for $P$. iwasakii from Guo \& Deng (2009): Pareas vindumi sp. nov. differs from all other described Pareas species by its the colouration. Furthermore it differs from Pareas margaritophorus (Jan, 1866) and $P$. macularius Theobald, 1868 by the much higher number of Sc in the single known female (61 vs. only 34-45 in females), by the Lo touching the orbit (vs. not touching), by the presence of a presubocular (vs. absence) and by the absent preocular (vs. present).

Pareas vindumi sp. nov. differs from $P$. carinatus (Boie, 1828) by the preocular absent (vs. present), by the prefrontal bordering the eye (vs. not bordering) and by the number of 
infralabials (6 vs. 7-10). From $P$. nuchalis Boulenger, 1900 it differs by its larger size, the number of Ve (178 vs. 195-213), a much lower number of Sc (61 vs. 105-113), in the labials not bordering the eye (vs. bordering), the Lo touching the eye (vs. not touching), and by the lack of a preocular (vs. present).

From P. boulengeri (Fig. 4) it differs by the lower number of supralabials (6 vs. 7-8), by the fact that only two supralabials touch the sublabial (versus usually 4 rarely 3 ); by the presence of a presubocular (vs. none) and by the lower number of infralabials (6 vs. 8 or rarely 7 or 9). $P$. boulengeri has a totally different colouration. In Pareas vindumi sp. nov., there are no postocular stripes (against 2), there is no mask like mark in the neck (against such a mark present) and there are no bands on the body (against 38-48 bands in the three types of $P$. boulengeri). The subcaudals are heavily mottled in Pareas vindumi sp. nov. (against a few scattered spots). There is considerable confusion in the literature about the determination of the species $P$. boulengeri, $P$. chinensis, $P$. monticola and $P$. formosensis. So the new species was explicitly compared to the syntypes of $P$. boulengeri.

From P. monticola (Fig. 5) it differs by the lower number of Ve (178 vs 182-189) and Sc (61 vs. 69-72, 84 in the holotype of Amblycephalus monticola [Boulenger, 1896]), by the lower number of supralabials (6 vs. 7), by the lower number of infralabials (6 vs. 7-9), and by the absence of a postocular (vs. presence).

$P$. monticola has a totally different colouration. In Pareas vindumi sp. nov., there are no postocular stripes (against 2), there is no mask like mark in the neck (against such a mark present) and there are no bands on the body (against 48-60 bands in three females of $P$. monticola). The subcaudals are heavily mottled in Pareas vindumi sp. nov. (against a few scattered spots ).

From the P. chinensis / formosensis-complex it differs by its larger size, by the lower number of Sc (61 vs. 65-80), by the lower number of supralabials (6 vs. 7-8), by the lower number of infralabials (6 vs. 7-9), by the Lo touching the eye (vs. not touching) and by the presence of a presubocular (vs. none).
From $P$. nigriceps it differs by the lower number of supralabials (6 vs.7), by the lower number of infralabials (6 vs. 7), by the smooth dorsal scales (vs. keeled in the 9 median rows) and by the not enlarged vertebral scales (vs. enlarged). $P$. nigriceps furthermore has a very characteristic coloration.

From P. stanleyi (Boulenger, 1914) it differs by the higher number of Ve (178 vs. 151-160), by the smooth dorsal scales (vs. keeled in the 13 median rows), by the not enlarged vertebral scales (vs. enlarged), by the presence of a subocular (vs. absent) and by the lower number of infralabials (6 vs. 7-9).

From P. hamptoni (Boulenger, 1905) it differs by its shorter tail (Relative TL 0.198 vs 0.242 0.291 ), by the lower number of Sc (61 vs. 73108 ), by the lower number of supralabials (6 vs. $7-8$ ), by the Lo touching the eye (vs. not touching) and by the absent preocular (vs. present).

Finally it differs from P. iwasakii (Maki, 1937) by its lower number of Ve (178 vs. 189-194), by the lower number of Sc (61 vs. 72-81), by the smooth dorsal scales (vs. keeled in the 5-7 median rows), by its vertebrals not enlarged (vs. enlarged) and by the lower number of infralabials (6 vs. 8-9).

Currently Pareas vindumi sp. nov. cannot be assigned to any species group in this genus, and based on the pholidosis it seems to be an isolated species. Very surprising is the high elevation of $1890 \mathrm{~m}$ a.s.l. at which the specimen was found. Only few snake species are known from such high elevations in Myanmar.

The discovery of several new species is not surprising considering the isolated geographical situation of the area, located between the Irrawaddi River and the Hengduan mountains area and the paucity of collections. More new species can be expected when the collected material has been worked through. Four more new snake species were described as a result of the CAS expeditions to Myanmar: Naja madalayensis Slowinski \& Wüster, 2000, Lycodon zawi Slowinski, Pawar, Win, Thin, Gyi, Oo \& Tun, 2001, Python kyaiktiyo Zug, Gotte \& Jacobs, 2011, and Dendrelaphis walli Vogel and van Rooijen, 2011. 
At present, five species of the genus Pareas are definitely known from Myanmar: $P$. carinatus, $P$. hamptoni, $P$. margaritophorus, $P$. macularius and Pareas vindumi sp. nov. $P$. macularius was regarded as a synonym of $P$. margaritophorus by several authors (Huang 2004, Guo \& Deng 2009). A review of the $P$. margaritophorus complex is underway. P. monticola was found close to the border of Myanmar in Mizoram Province, India (Laltanpuia, et al. 2008; own observations, Fig. 5) and can be expected to be found in Myanmar.

\section{Acknowledgements}

A special thank goes to Jens Vindum and Alan Leviton (CAS), who made it possible for me to describe this species, and all the staff of the CAS for their hospitality during my visit and the efforts they made to provide this wonderful collection from Myanmar. I thank Patrick David (MNHN) for his advice and the review of the first draft of this manuscript and Gerrut Norval (ABEERU) for the review of the language and text. Furthermore I want to thank the following people, who gave me access to specimens in their care and helped me while visiting their respective institutions: Colin McCarthy and Patrick Campbell (BMNH), Jens Vindum and Alan Leviton (CAS), Yuezhao Wang, Xiaomao Zeng, Jiatang Li and Ermi Zhao (CIB), Ding Lee (DL), Alan Resetar (FMNH), Alain Dubois, Ivan Ineich and Annemarie Ohler (MNHN), Irvan Sidik (MZB), Heinz Grillitsch, Silke Schweiger and Richard Gemel (NMW), Pim Arntzen and Ronald de Ruiter (RMNH), Gunther Köhler and Linda Acker (SMF), Dennis Rödder and Wolfgang Böhme (ZFMK), Ronald Vonk and Hielke Praagman (ZMA), Mark-Oliver Rödel and Frank Tillack (ZMB), and Frank Glaw and Michael Franzen (ZSM). Finally I would like to thank Ivan Ineich (MNHN), Olivier S.E. Pauwels, and Jakob Hallermann for reviewing the manuscript.

\section{Literature cited}

Boulenger, G.A., 1896. Catalogue of the Snakes in the British Museum (Natural History). Volume III. Containing the Colubridae (Opisthoglyphae and Proteroglyphae), Amblycephalidae and Viperidae. London, British Museum (Natural History): 727 + $25 \mathrm{pls}$.

Dowling, H.G., 1951. A proposed standard system of counting ventrals in snakes. British Journal of Herpetology, 1: 97-99.
Götz, M., 2002. The feeding behavior of the snaileating snake Pareas carinatus Wagler, 1830 (Squamata: Colubridae). Amphibia-Reptilia, 23: 487-493.

Guo, K. and X. Deng, 2009. A new species of Pareas (Serpentes: Colubridae: Pareatinae) from the Gaoligong Mountains, southwestern China. Zootaxa, 2008: 53-60.

Guo, Y., Y. Wu, S. He and E. Zhao, 2011. Systematics and molecular phylogenetics of Asian snail-eating snakes (Pareatidae). Zootaxa, 3001: $57-64$.

Huang, Q.-Y., 2004. Pareas chinensis (Barbour, 1912) should be a junior synonym of Pareas formosensis (Van Denburgh, 1909) [In Chinese]. Sichuan Journal of Zoology, 23: 209-210.

Laltanpuia, T.C., C. Lalrinchhana, Lalnunsanga, Lalrotluanga, R. Hmingthansanga, A. Kumari, V. Renthlei, S. Lalrintluangi, and H.T. Lalremsanga, 2008. Snakes (Reptilia: Serpentes) of Mizoram University Campus, Tanhril, Aizawl with notes on their identification keys. Science Vision, 8: 112127.

Loredo, A.I., P.L. Wood Jr, E.S.H. Quah, S. Anuar, L.F. Greer, N. Ahmad, and L. Grismer, 2013. Cryptic speciation within Asthenodipsas vertebralis (Boulenger, 1900) (Squamata: Pareatidae), the description of a new species from Peninsular Malaysia, and the resurrection of $A$. tropidonotus (Lidth de Jude [sic], 1923) from Sumatra: an integrative taxonomic analysis. Zootaxa, 3664: 505-524 .

Ota, H., J.-T. Lin, T. Hirata, and S.-L. Chen, 1997. Systematic review of colubrid snakes of the genus Pareas in the East Asian Islands. Journal of Herpetology, 31: 79-87.

Pyron, R.A., F.T. Burbrink, G.R. Colli, A.N. de Oca, L.J. Vitt, C.A. Kuczynski, and J.J. Wiens, 2011. The phylogeny of advanced snakes (Colubroidea), with discovery of a new subfamily and comparison of support methods for likelihood trees. Molecular Phylogenetics \& Evolution, 58: 329-342.

Rao, D.-Q. and D.-T. Yang, 1992. Phylogenetic systematics of Pareatinae (Serpentes) of Southeastern Asia and adjacent islands with relationship between it and the geology changes [In Chinese]. Acta Zoologica Sinica, 38: 139-150. 
Appendix I: Examined material

(Localities as given with the specimens)

Aplopeltura boa (2 specimens): Indonesia: ZSM 512/1909 "Batang Kwis, Sumatra”; ZSM 363/1920 "Nias".

Asthenodipsas laevis (11 specimens): Indonesia: MZB 2728 "Bukit Lawang Sumatra"; NMW 13382, NMW 21823:2 "Padang, Sumatra"; RMNH 986A-C (Lectotype and paralectotypes of Amblycephalus laevis) "Java"; SMF 20788-89 "Ranau, Sumatra"; SMF 81195 "Sumatra"; ZMA 16245 "Banka”; ZSM 126/1947 "Niederländisch Indien".

Asthenodipsas lasgalensis (3 specimens): Malaysia: ZFMK 53098 "Cameron Highlands, Tanah Rata"; ZMB 57112-13 "Cameron Highlands, zw. Markt und Trinkat".

Asthenodipsas malaccanus (10 specimens): Indonesia: MNHN 1939.0201-0204 (Syntypes of Asthenodipsas malaccanus ventrilineatus Angel, 1941) "Batavia, Java"; MZB 3592 "Bengkulu, Sumatra"; NMW 28126:1-2 "W-Sumatra"; ZSM 143/1907 "Maveling, WBorneo"; Malaysia: SMF 32580 "Perak"; Thailand: ZFMK 45131 "Satun".

Asthenodipsas tropidonotus (5 specimens): Indonesia: MZB 1816 "Mt. Pesogi, Lampung, Sumatra"; MZB 3725 "Kabu Peraku, Lampung, Sumatra; NMW 28126:3-4 "Padang, Sumatra"; University of Padang no number: "Western Sumatra".

Asthenodipsas vertebralis (1 specimen): Malaysia: ZMB 52072 "Bukit Frazer".

Pareas boulengeri (4 specimens): China: MNHN 1912.0349-0351 (Syntypes of Amblycephalus boulengeri) "Kouy Tcheou"; CIB 10084 "Fangxiang Village, Leishan County, Guizhou Province".

Pareas carinatus (10 specimens): Indonesia: RMNH 954 "Java"; SMF 20797 "Buitenzorg, Java; SMF 25995 "Bogor, Java"; SMF 37825-26 "Ranau, Sumatra"; SMF 55295 "Karimundjava, main island, Java Sea" (Syntypes of Amblycephalus carinatus); ZSM 154/1999 "Gonoung Rinteh, Sultanat Deli, Sumatra", Myanmar: CAS 240362 "Kyaihto Township, Kinpon Chaung Village, Yae Myaung Lay Stream, $17^{\circ} 24^{\prime} 21.7^{\prime \prime}$ N, $97^{\circ} 04^{\prime} 38.6^{\prime \prime}$ E”.

Pareas chinensis (10 specimens): China: CIB 10145 (64I6435), CIB 10147 (64I6667), "Guadun, Chong'an County, Fujian Province"; CIB no number, Shiwan mountain; Shangsi County, Guangxi Provnce"; FMNH 232812-14 "Sichuan, Hongya Xian: 9 km W Bin Ling, Wa Shan camp"; FMNH 24988-89 "Ch'ungan Hsien, Fujian Province"; ZMB 65431, 27660 "Talifu, Yunnan Province".

Pareas formosanus (8 specimens): China: DL 0001 "Jiguan Mt., Szechuan"; Taiwan: FMNH 169392 "Yang-Ming-Shan, Taiwan "; FMNH 127998, 169315 "Yang-ming-shan: Yung-foh-lee, Taiwan"; FMNH 169395 "Taiwan, Yang-ming-shan: Mt. Agr. Area"; NMW 28130:1 "Alikang"; NMW 28130:23 "Kosango"; ZMB 30585 "Suisharya".

Pareas hamptoni (5 specimens): China: PSGV 1024 "Hainan"; ZMB 65430 "Loshiang, Yao Shan, Guangxi", Myanmar: BM 1904.4.26.16 (Holotype of Amblycephalus hamptoni) "Mogok, Upper Burma"; Vietnam: MNHN 1908.0206 (Holotype of Eberhardtia tonkinensis) "LaoKay"; FMNH 255567 "Nghe An, Tuong Duong Dist: Pu Mat Nature Reserve, wet evergreen forest along Khe Mat stream, $19^{\circ} 03^{\prime} \mathrm{N} 104^{\circ} 37^{\prime} \mathrm{E}, 600 \mathrm{~m}$ ".

Pareas macularius (15 specimens): China: CIB 10155 (725035) "Jianfengling Mountain, Hainan. 800m"; Laos: MNHN 1994.0743 "Haut Laos"; MNHN 2005.0232 "Long Nai Tai"; Myanmar: BM 1946.1.20.8 (Holotype of Pareas macularius) "Tenasserim"; CAS 206620 "Bago Division: Bago Yoma, $18^{\circ} 52$ ' 59.8” N, 95 52' 44.9 E”; CAS 235218 Chin State: Ke Har Stream, Kanpetlet Town, Mindat District, $21^{\circ} 12^{\prime}$ 20.2” N, 9403’01.1” E, 4296 ft; CAS 235359 "Chin State: Old Kanpetlet Township, Mindat District and near Natmataung National Park office, in Tin Nyo house, 21 $12^{\prime}$ 16.7" N, 94 02' 07.9" E, 5937 ft”; CAS 241270 "Kachin State: Mohnyin Township, Indawgyi Wildlife Sanctuary, in the vicinity of Kyang Kyar Village, 25 18' 12.5" N, 96² 21' 15.0"E, 850 ft”; CAS 245296 "Sagaing Division: Lahe Township, Laung Nguk Village, 26 09' 22.4"N, 95 31' 59.8"E, 2721 ft”; CAS 245377 "Sagaing Division: Laung Nguk Village, Lahe Township, $26^{\circ} 09^{\prime} 17.8^{\prime \prime} \mathrm{N}, 95^{\circ} 31^{\prime} 17.3^{\prime} \mathrm{E}$, 2857 ft"; CAS 247899 "Tanintharyi Division: Dawei District, Yaephyu Township, TNR,

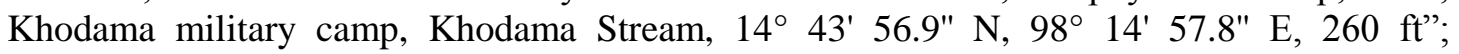


Thailand: FMNH 135331 "Loei Prov, Dansai Dist: Na Phung (vill), Ban Khok (subv), Namlang Mt, 1780m"; Vietnam: FMNH 175332 "Ngan-Son"; ZFMK 82925 "Nghe An"; ZFMK 86446 "Quang Binh, Phong Nha Ke Bang NP".

Pareas margaritophorus (29 specimens): Cambodia: FMNH 256973 "Stung Treng Prov, Siem Pang Dist: Virachey National Park, $14^{\circ} 18^{\prime} 52.8^{\prime \prime N} 106^{\circ} 35^{\prime} 49.9^{\prime \prime E}$, 340m"; NMW 28128:4 "Cambodia"; ZFMK 92636-37, 90378 " Siam Reap, Phnom Kulen NP"; China: CIB 10160 (705015) "Yuling, Hainan"; CIB 83792 (665082), CIB 10157-8 (665080-1) "Diaoluo Shan, Hainan"; CIB 10162 (64III5159) "Wuzhi Shan, Hainan"; FMNH 256973 "HongKong"; SMF 20790 "Lo Fou Shan, Kanton" (Holotype of Pareas moellendorffi); SMF 20791-92 "Hongkong"; ZSM no number "Hong Kong"; Malaysia: ZFMK 70584 "Area North of Kuala Lumpur"; Thailand: MNHN 0599 (Holotype of Leptognathus margaritophorus) "Thailande"; ZFMK 76107 "Chiang Mai, Mesa Valley"; Vietnam: FMNH 71704-05 "Dalat"; NMW 28129:3, NMW 28128:3 “Tonkin"; NMW 28128:5 “Annam"; NMW 28128:6 "Phuc Son, Annam"; ZFMK 80664 "Quang Binh, Phong Nha Ke Bang NP"; ZFMK 81479 Ha Tinh, ky Anh-Ke Go; ZFMK 82924 Nghe An; ZFMK 95197 "Quang Ninh, Bai Tu Long NP"; ZSM 2271/0 "Tonkin".

Pareas monticola (3 specimens): China: CIB 10163 "Tibet"; India: NMW 28127 "Darjeeling"; Myanmar: CAS 224415 "Nagmung Township, Hkakabo Razi National Park, between Ngawar Village and Lon Nut Village, $27^{\circ} 46^{\prime} 05.5^{\prime \prime}$ N, 97 49' 07.7" E".

Pareas nuchalis (7 specimens): Indonesia: FMNH 131635-36 "Sarawak, 4th Div: Niah"; FMNH 239902-03 "Sabah, Tenom Dist: Crocker Range National Park, Purulon camp, Area I, 5¹3'N

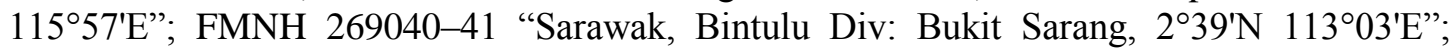
USNM 070863 "Sumatra, Kepahiang”.

Pareas stanleyi (4 specimens): China: CIB 10165 "Fujian"; FMNH 24990-92 "Fukien, Ch'ungan Hsien".

\section{Appendix II: Characters used}

Morphometry: Snout-vent length (SVL) in $\mathrm{mm}$, Tail length (TaL) in $\mathrm{mm}$, Total length (TL) in mm, Relative tail length (rel TL) TaL/TL.

Scalation: Dorsal scale rows at neck (at 1 head length behind head)/ at mid-body/ at vent (one head length before vent), Number of keeled dorsal rows, Presence of apical pits, Enlargement of vertebrals, Ventral plates, Number of preventrals, Ventrals notched, keeled or angulated or none of these, Subcaudal plates, Cloacal (anal) plate: 1: single and 2: divided, Number of loreal scales at left/right, Loreal scales touching eye at left/right, Number of supralabials at left/right, Numbers of the supralabials touching the orbit at left/right, Numbers of the supralabials touching subocular at left/right, Largest supralabials left/right, Number of infralabials at left/right, Number of infralabials contacting each other, Number of preoculars at left/right, Number of postoculars at left/right, Subocular fused with postocular, Number of posterior presuboculars at left/right, Number of suboculars at left/right, Number of nasals at left/right, Number of anterior temporals at left/right, Number of posterior temporals at left/right, Prefrontal bordering the eye.

Pattern: $\quad$ Body colour, Number of bands on body, Number of bands on tail, Ornamentation in neck, Presence and number of postocular stripes, Colouration of tail venter, Banding of venter, Speckling of venter. 


\section{PLATE 1}
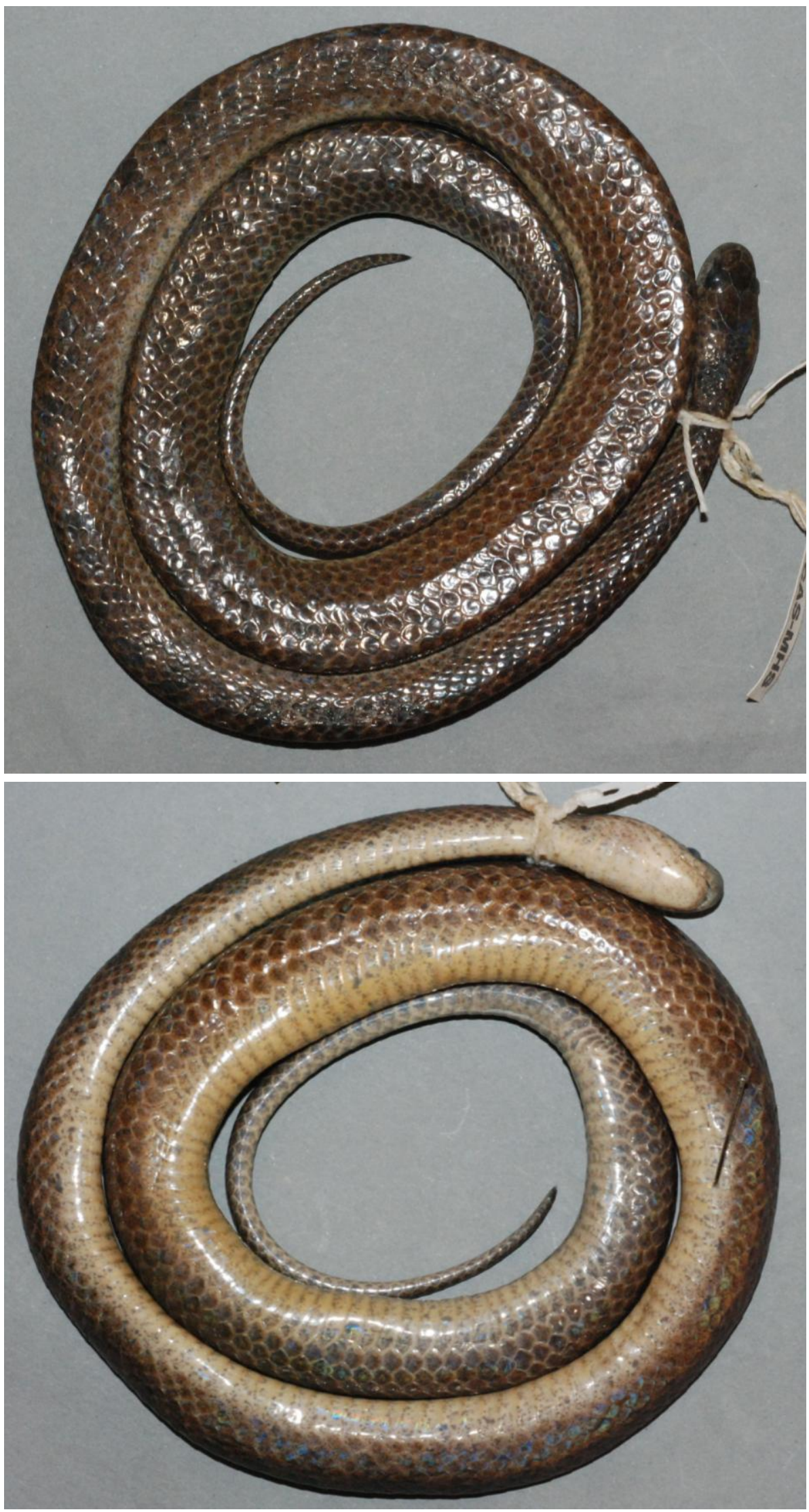

Figure 1: Dorsal (above) and ventral (below) views of the holotype (CAS 248147) of Pareas vindumi sp. nov. 


\section{PLATE 2}

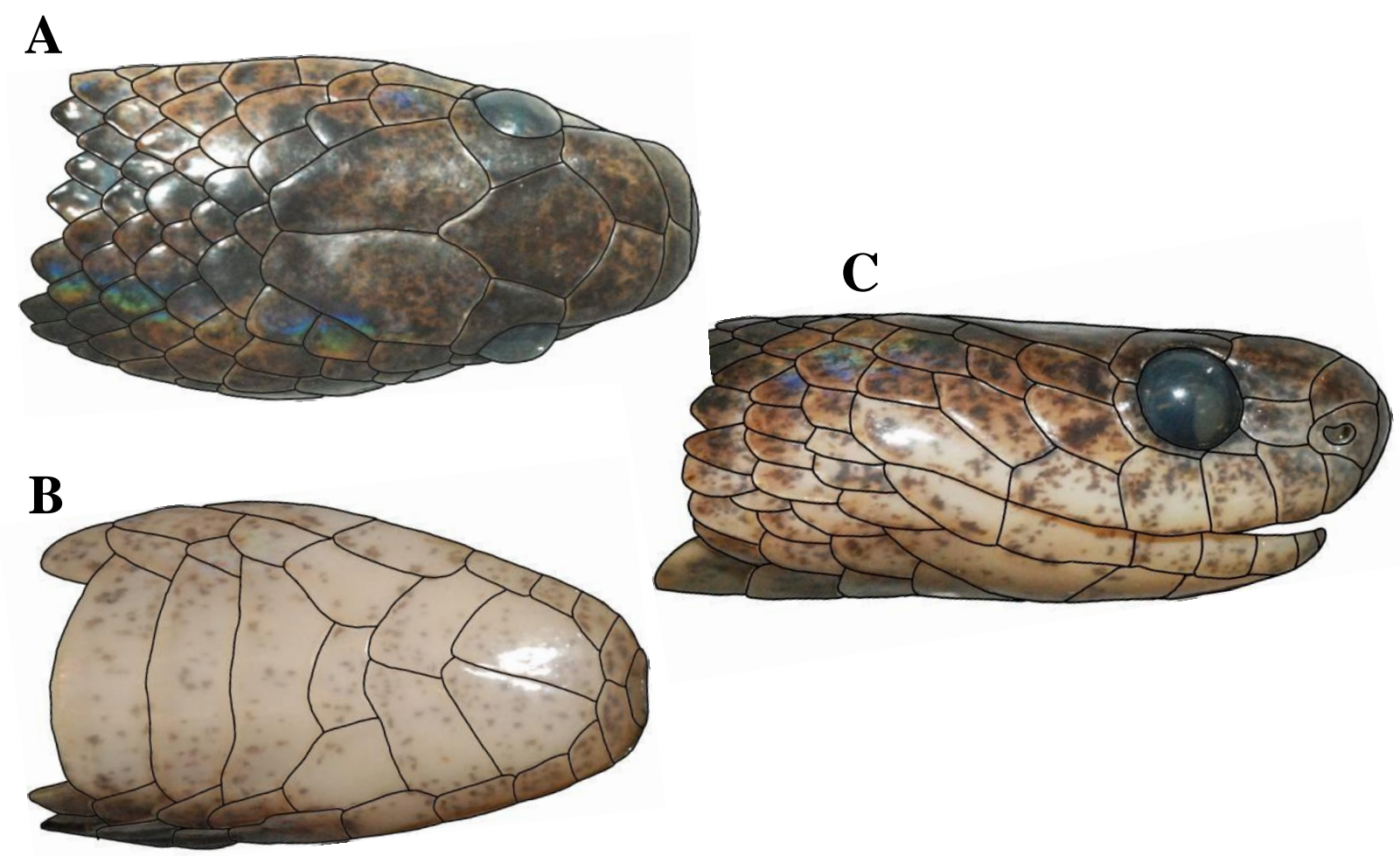

Figure 2: (A) dorsal, (B) ventral, and (C) lateral views of the head of the holotype (CAS 248147) of Pareas vindumi sp. nov.

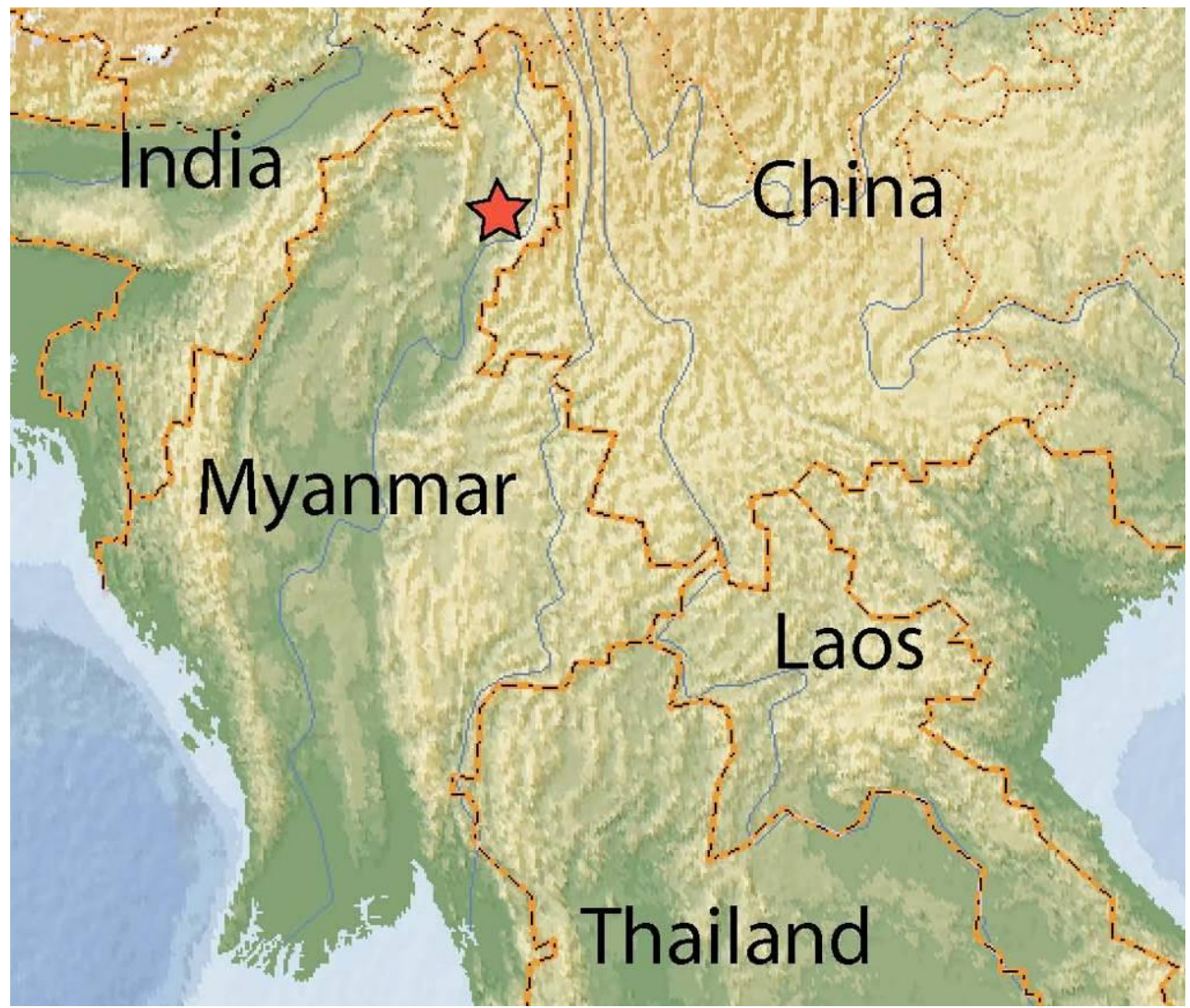

Figure 3: Map indicating the type locality of Pareas vindumi sp. nov.. 


\section{PLATE 3}

\section{A}

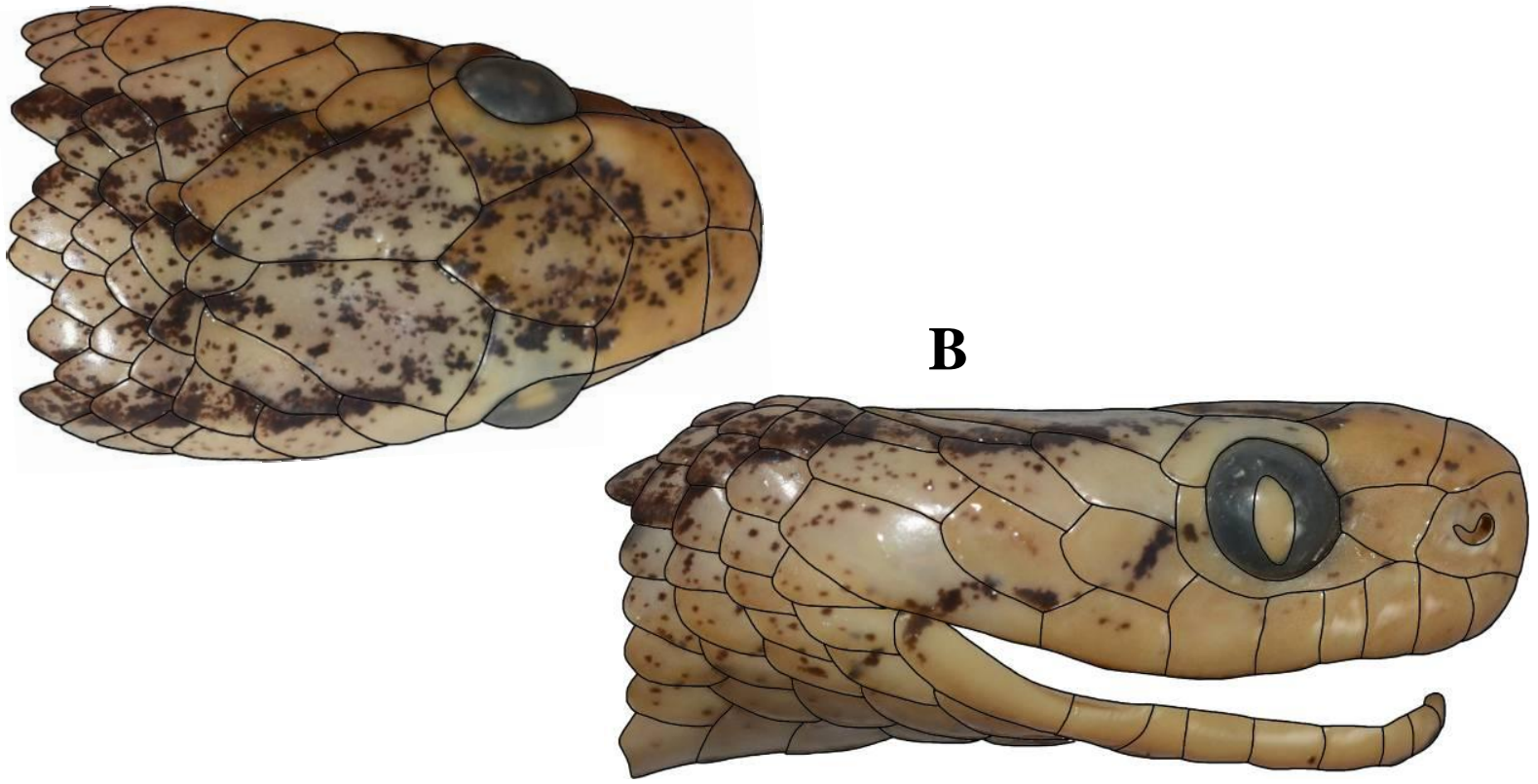

Figure 4: (A) dorsal and (B) lateral views of the head of one of the syntypes (MNHN 1912.0351) of Pareas boulengeri (Angel, 1920), China

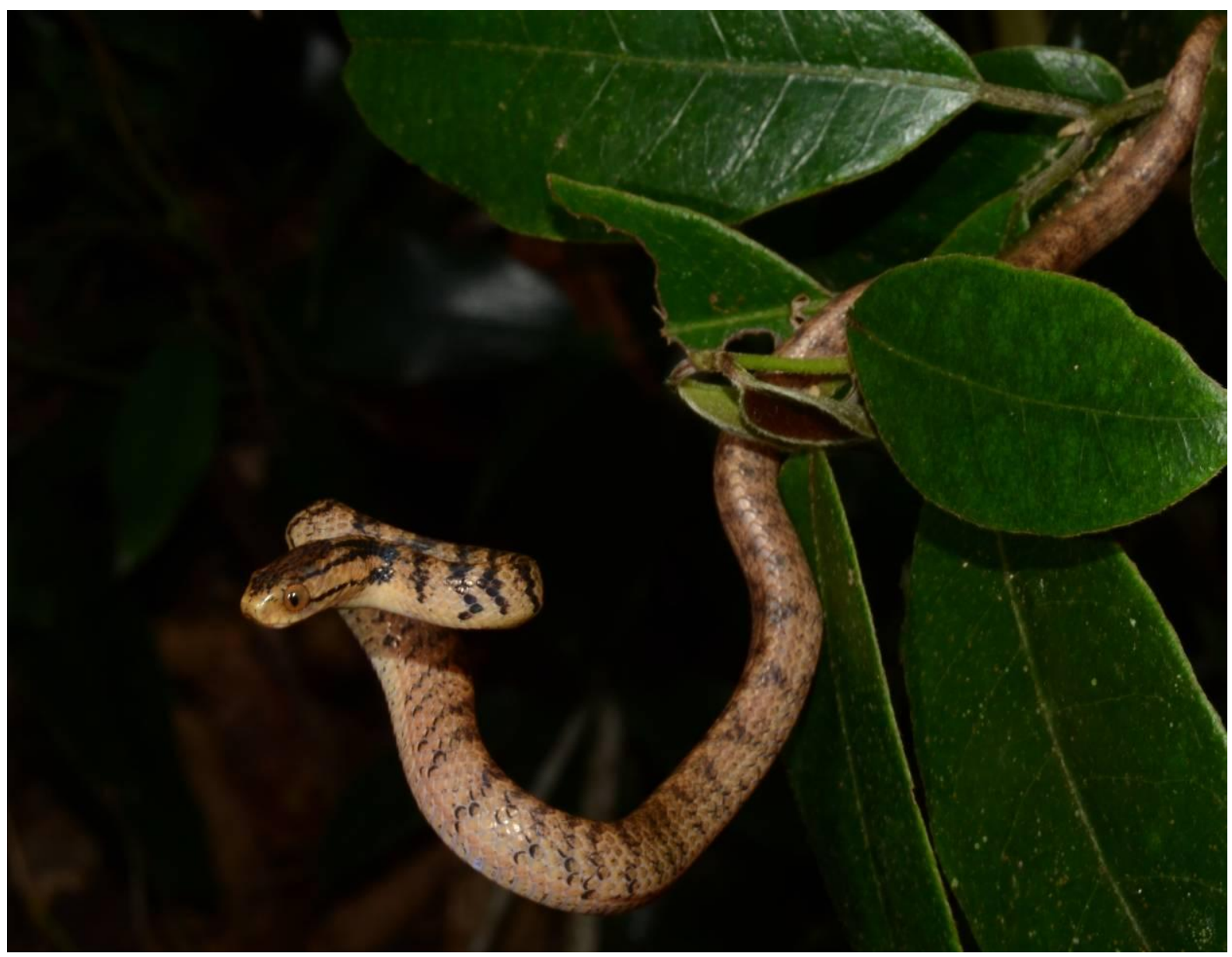

Figure 5: Live Pareas monticola, from Mizoram, India. 